\title{
ÜNAK/OCLC Konsorsiyum Çalışmaları
}

\section{UNAKIOCLC Consorsia Studies}

\section{Adile Günden}

\begin{abstract}
Öz
ÜNAK, OCLC ile bir konsorsiyum kurmuştur. Makalede, OCLC veri tabanlan, özellikleri, Türkiye'nin hedefleri ve yararlan, bu konsorsiyum içinde yer alan araştırma kurumları anlatılmaktır.

Anahtar sözcükler: Kütüphane konsorsiyumları, OCLC, Veri tabanları, ÜNAK.

Abstract

ÜNAK had established with OCLC the consortium. The article considers the databases of OCLC and identifies the OCLC in conjunction with its benefits and goals for Turkey. The research institutions of the mentioned consortium are also explicated.
\end{abstract}

Keywords: Library consortia, OCLC Databases, UNAK

\section{OCLC ve OCLC Veri Tabanları}

OCLC (Online Computer Library Center), 82 ülkeden 41.000 kütüphaneye hizmet veren, kar amacı gütmeyen üyelik esasına dayalı çalışan bir organizasyondur. Kütüphaneler ve kullanıcılarına yönelik olarak dünya üzerindeki bilgiye daha kapsamlı ve düşük maliyetle erişim olanağı sağlamayı hedeflemektedir.

OCLC, üye kütüphanelerin kaynaklarını paylaşmak ve masraflarını azaltmak amacıyla 1967'de üniversite rektörlerince kurulmuş ve 1971'de üye kütüphaneler için kütüphanecilerle "Online Shared Cataloging System" (paylaşıma açık çevrimiçi kataloglama sistemi) oluşturmuştur. Kütüphanelerarası ödünç verme hizmetinin başladığı 1979 yılından bugüne kadar dünyadaki

“ ÜNAK Yönetim Kurulu Başkanı. Hacettepe Üniv. Kütüphane ve Dokümantasyon Dairo Başkan Yardımcısı (gunden@hacettepe.edu.tr) 
6700 kütüphane arasında 116 milyondan fazla ödünç verme işlemi gerçekleștirilmiştir. Bir danışma aracı olan FirstSearch 1991'de hizmete girmiştir ve halen 19.246 kütüphane tarafından kullanılmaktadır."

OCLC'nin gelişim hızını belirtmek için, OCLC üyesi kütüphanelerin herhangi birinden her 15 saniyede bir WorldCat'e bir kayıt eklendiğini, her 5 saniyede bir WorldCat kullanılarak kütüphanelerarası istek formu doldurulduğunu, her 2 saniyede bir ise bir kütüphane kullanıcısının FirstSearch üzerinden WorldCat taraması yaptığını söylemek yeterli olacaktır.

OCLC, 1 Ocak 2002 tarihinden itibaren Avrupa'daki üye kütüphanelerini, daha iyi hizmet verebilmek amacıyla, OCLC/PICA adı altında yeniden organize etmiştir. Türkiye, merkezi Paris'de bulunan Güney Avrupa grubunda yer almaktadır.

FirstSearch, Web tabanlı çevrimiçi danışma hizmetidir. Önemli bibliyografik ve tam metin veri tabanları ile danışma kaynakıarını aynı ara yüzle tarama, yerel katalog veya topłu kataloğa bağlantı, dünyadaki üye kütüphanelerin koleksiyonunu izleme ve belge sağlama olanağı sunmaktadır. FirstSearch içindeki bibliyografik ve konu veri tabanı sayısı 70'e ulaşmıştır. FirstSearch kapsamında hizmete sunulan OCLC ürünü veri tabanları ve temel özellikleri şöyle özetlenebilir:

Articlefirst : Bilim, teknoloji, tıp, sosyal ve beşeri bilimler, ekonomi gibi her konuda 13 bin süreli yayından 12.7 milyon makale bilgisi içerir ve her gün güncellenir. Tarama sonuçlarından tam metin erişimi olan veri tabanlarındaki makalelere bağlantılar erişim kolaylığı sağlamaktadır.

Contentsfirst : ArticleFirst içindeki dergilerin içindekiler saytalarını içermekte idi, 2002 yılında OCLC ArticleFirst ile birleştirilerek ayrı bir veri tabanı olarak sunulmasından vazgeçildi.

ECO - Electronic Collections Online : Kullanıcılar, 64 yayınevinden 4000 kadar dergideki bir milyondan fazla makalenin bibliyografik bilgilerini ve özetini görebilirler ve kurumları abone ise, bu dergilerin içindeki makalelere tam metin olarak erişebilirler. OCLC - ECO nun özellikleri:

" OCLC (2002.13.4) OCLC system statistics. [Cevrimiçi]. Elektronik adres: http://www.oclcorg/news/product/statistics. shtm [19 Nisan 2001]. 
o Tam metin erişim olarak abone olduğunuz dergilere, bu yıllara ait erişim hakkınızın kaybolmaması.

- Hiçbir dergide ambargo uygulanmaması (5 yayınevi hariç tüm dergiler kendi sunucuları üzerinden hizmete sunulduğu için).

o FirstSearch-ECO'da bibliyografik künyesine erişilen makalelerin tam metninin çok kısa sürede ve uygun fiyata temini.

- Şifre ve yetki numaraları ile istenilen her türlü istatistiğin alınabilmesi.

- Erişilen makalenin isteyen kişiye istenilen şekilde gönderilmesi için hiçbir kısıtlamanın olmaması.

- ECO içinde bulunan ve kurumların basılılarına abone oldukları dergilerin elektronik kopyalarına ücretsiz erişim sistemi (PSP - Print Subscription Program).

- Yakın gelecekte içindekiler sayfasına da erişim olanağı.

- ECO'da dergileri yer alan yayınevlerinin listeși Ek'te verilmiştir.

NetFirst : Internet üzerinden erişilebilen 175.000 nitelikli bilgi kaynağının URL adreslerini içeren bir veri tabanıdır. Bir tarama motoru niteliğindedir ve Web sayfaları, elektronik tartışma grupları, video katalogları, FTP siteleri, listeler, bültenler, elektronik dergiler, Gopher gibi kaynakları, LC konu başııkları ve Dewey Onlu Sınıflama'ya göre taramaya olanak tanır ve bu kaynaklara bağlantı sağlar.

PapersFirst : British Library Document Center tarafından 1993 yılından bu yana toplanan bütün dünyadan konferanslarda sunulmuş 3.7 milyon bildirinin bibliyografik bilgilerine erişim sağlar. Kullanıcılar, istedikleri bildirilere tam metin olarak erişmek istediklerinde FirstSearch içindeki sipariş servisi aracılığı ile British Library Document Center'den sipariş edebilmektedirler.

ProceedingsFirst : British Library Document Center tarafından 1993 yıIından bu yana toplanan butün dünyadaki 75.000 kadar konferans ve bildirilerine ait bilgilere erişim sağlar. Kullanıcılara, istedikleri bilgileri British Library Document Center'den sipariş edebilme olanağı vermektedir. 
Union Lists of Periodicals (Union Lists) : OCLC'ye üye kütüphanelerin süreli yayın toplu kataloğudur. WorldCat içinde bulunan 750.000 üzerindeki süreli yayın kaydına ait 8 milyonun üzerindeki dergi mevcudunu içeren bibliyografik kayıt ve yerel kayıtlarına erişmek mümkündür.

WorldCat (The OCLC Online Union Catalogue) : Bütün dünyadaki OCLC üyesi kütüphariórerin koleksiyonlarındaki 400 dilde, kitap, video, ses kayıtla$\mathrm{rl}$, haritalar, notalar, el yazmaları, arşivler vb. ile CORC (Cooperative Online Resources Catalogue) kayıtlarını -49 milyonu aşmıştır- içerir. Gelişimi, her 15 dakikada eklenen bir kayıtla her 6 ayda bir milyon kayıt artarak devam etmektedir.

PAIS International : Genel anlamda kamu yönetimi ve sosyal bilimler konusunda 120 ülkeden dergi, kitap, rapor, gri yayıniar, kamu yayınları ve Internet kaynaklarına bibłiyografik erişim sağlayan bir veri tabanıdır. Ingilizce, Fransızca, Almanca, Italyanca, Portekizce ve Ispanyonca 500.000'e yakın kaynağın bibliyografik bilgisi ve özetini, ayrıca web kaynakłarına ve yayıncı sitelerine bağlantılar bulunmaktadır. Kapsamı, 1972 yılından bugününe kadardır ve aylık güncellenmektedir. Konsorsiyum paketi dışında olan PAIS International'a abone olan kurumlar FirstSearch arayüzü ile erişebilmektedir.

MEDLNE : Konsorsiyum paketi içinde yer alan bibliyografik veri tabanlarından birisidir. National Library of Medicine tarafından yayınlanan Index Medicus, Index to Dental Literature ve International Nursing Index'deki 11 milyonun üzerinde kaynağı kapsamaktadır. Hergün güncellenen veri tabanı, 1965 yılından itibaren tıp, diş hekimliği ve hemşirelikle ilgili bütün alanları içermektedir.

ERiC : Eğitim konularında aylık yayınlanan Resources in Education (RIE) ve Current Index to Journals in Education (CIJE)'da yer alan bir milyona yakın makale ve raporları tarama olanağı veren bibliyografik bir veri tabanıdır. FirstSearch içinde erişilebilen tam metin makalelere bağlantı sağlayan, aylık olarak güncellenen veri tabanı, 1966 yılından günümüze kaynakları listelemekte ve istenirse doküman sağlama olanaklarını da göstermektedir. 
GPO Monthly Catalog, U.S. Government Printing Office tarafından Kongre raporları da dahil olmak üzere çok sayıda kamu kurumunun 500.000 'in üzerinde yayınını, 1976 yılından bugüne listemektedir ve aylık olarak güncellenmektedir.

\section{Tam metin veri tabanlan:}

WilsonSelectPlus : Konsorsiyum paketi içinde yer alan tam metin veri tabanıdır. H.W.Wilson Company'nin bilim, beşeri bilimler, eğitim, işletme gibi konularda yayınladığı 1400 'ün üzerinde derginin tam metinlerine, FirstSearch içinde veya ayrı olarak erişim sağlanmış olup, yayınladığı 21 indeks de FirstSearch'ün veri tabaniarı arasındadır.

World Almanacs : The World Almanac and Book of Facts ve World Almanac Knowledge Source'a tam metin erişim olanağı veren uluslararası ve geniş kapsam/ı bir danışma kaynağıdır.

BioOne : Biyoloji, tıp, çevre ve ekoloji ile ilgili konularda önemli bilimsel dergilerden oluşan elektronik bir koleksiyondur. Bilimsel ve kâr gütmeyen örgütlerin yayınlarını tek bir koleksiyon olarak kullanıçılara sunmayı amaçlayan BioOne veri tabanında, Mayıs 2002'de 49 dergiye tam metin erişim olanağı bulunmakta ve gelecekte yayın sayısının arttırıması planlanmaktadır. ECO içinde yer alan veri tabanı için altı üniversitenin katıldığı bir alt konsorsiyum oluşmuştur.

Ayrıca OCLC her ay bir veri tabanını ve ECO'da bulunan bir dergiyi sınırsız olarak herkesin kullanımına açmaktadır. Bu deneme süreci için özellikle OCLC'nin çok kullanılan bibliyografik veri tabanları seçilmektedir.

\section{ÜNAK/OCLC Konsorsiyumunun Oluşumu}

Üniversite ve Araştırma Kütüphanecileri Derneği (ÜNAK), çağımızda hızla gelişen enformasyon ürün ve teknolojilerini tanıtmak, kütüphanecileri bu konularda bilgilendirmek ve çalışmalarını kolaylaştırmak amacıyla seminerler dủzenlemektedir. Derneğimiz, OCLC'yi ilk kez 5 Nisan 1993 tarihinde Boğaziçi Üniversitesinde verilen seminerle Türkiye'ye tanıttı. Avrupa müdürü Janet Mitchell tarafından verilen seminerin başlığı; "OCLC, an International 
Bibliographic Facility for Resource Sharing between Libraries" idi. Ancak o zaman Türkiye'deki araştırma merkezlerinin alt yapısı çevrimiçi hizmetlerinin alınması için yeterli değildi ve OCLC ürünleri, CD-ROM olarak Türkiye'de kullanımaya başlandı. 2000 yılına gelindiğinde ise ULAKNET kurulmuş ve birçok kurum alt yapı sorunlarını çözmüştü. Derneğimiz 2, kez OCLC'yi Türkiye'ye davet etti. ITS'in işbirliği ile OCLC FirstSearch paketi kapsamında bulunan bilgi bankałarının tanıtımı ve konsorsiyumu için 19 Eylül 2000'de Ankara'da Orta Doğu Teknik Üniversitesinin, 21 Eylül 2000'de İstanbul'da Koç Üniversitesinin ev sahipliğinde iki seminer düzenledi. OCLC'den Nicholas R.Rawson ve John Dowd tarafından verilen ve tüm gün süren seminerler, öğretim elemanları, kütüphane yöneticileri ve kütüphanecilerden oluşan büyük bir katılımcı grup tarafından ilgi ile izlenmiş ve tarışmalar konsorsiyum alternatifleri üzerinde yoğunlaşmıştır. OCLC, veri tabanları aboneliği için Türkiye'de bir konsorsiyum kurulabilmesi amacıyla temasa geçen Derneğimizi, ITS'in desteğiyle "Türkiye Temsilicisi" (body) olarak seçmiştir.

Seminerleri takiben OCLC FirstSearch içerisinde yer alan WorldCat, ArticleFirst, ECO (Electronic Collection Online), NetFirst, PapersFirst, ProceedingsFirst, Union List of Periodicals ile ERIC, GPO, MEDLINE gibi önemli veri tabanları, ayrıca tam metin veri tabanlarından H.W. Wilson Select Journals Plus ve World Almanac'dan oluşan bir bilgi kaynakları paketi, 39 üniversitenin deneme kullanımına açılmıştır.

15 Ekim-15 Aralık 2000 tarihlerinde verilen deneme süresi devam ederken 24 Kasım 2000 tarihinde, Ankara'da Hacettepe Üniversitesi Beytepe Kütüphanesinde yapılan toplantıda kullanım istatistikleri değerlendirilmiş ve abone olunacak veri tabanlarının seçimi yapılmıştır. Bu toplantı sonrası, 15 üniversitenin katılma kararı ile 4 Aralık 2000'de ÜNAK/OCLC Konsorsiyumu, "OCLC FirstSearch Base Package + Full Text" olarak kurulmuş ve bir üniversitenin daha katılımıyla üye sayısı 16'ya ulaşmıştır. 2001 yılındaki Konsorsiyum üyesi üniversite ve araştırma kurumları şunlardı:

Ankara Üniversitesi

Boğaziçi Üniversitesi

Çukurova Üniversitesi

Dokuz Eylül Üniversitesi
Doğu Akdeniz Üniversitesi

Ege Üniversitesi

Erciyes Üniversitesi

Hacettepe Üniversitesi 
Mersin Üniversitesi

Ondokuz Mayıs Üniversitesi

Pamukkale Üniversitesi

Selçuk Üniversitesi
Trakya Üniversitesi

Yüzüncü Yll Üniversitesi

GATA

ULAKBIM

\section{Konsorsiyumun Değerlendirilmesi ve Geliştirilmesi}

IItk ÜNAKJOCLC Konsorsiyum Toplantısı, "Making the Most of FirstSearch" temasıyla 18-19 Mayıs 2001 tarihinde Kapadokya'da yapıldı. Toplantıda ilk gün, FirstSearch yenilikleri, özeliłkleri, olanakları, tarama teknikleri ve arayüzleri; 2. gün ise tam metin elektronik dergilere ulaşım (ECO), doküman alımı, erişim seçenekleri, istatistik ve yönetim modülleri ile kataloglama modülü (Worldcat), CORC, ILL ve OCLC bünyesine yeni katılan "PAIS International" veri tabanı konusunda, kurumların temsilcilerine OCLC uzmanları John Dowd ve Simon Day tarafından seminer verildi. Seminerin sonunda yalnız üye kütüphanelerin yetkililerinin katıldığı toplantıda;

- ECO'da bulunan 3865 dergiye tam metin deneme erişiminin sağlanması ve istatistiklere göre yayınevlerinin seçimi,

- Worldcat'in Online Cataloging ve CORC için deneme kullanımı istenmesi,

- PAIS International (Public Affairs International Service) verì tabanı için deneme istenmesi,

- Bu toplantıların düzenli olarak her yıl Mayıs ayında tekrarlanması kararları alındı.

Bu kararlar doğrultusunda "PAIS International" veri tabanı ile ECO'da bulunan 3865 dergi, tam metin olarak Konsorsiyum üyelerine 20 Eylül 2001 tarihinde erişime açıldı ve 31 Ekim 2001 tarihine kadar açık kaldı. Toplantıyı takiben tüm üniversitelere yapılan duyuru sonucunda talep eden kurumlara ise 1-31 Ekim 2002 tarihłerinde deneme erişimi sağłandı.

WorldCat Online Cataloguing ve CORC için deneme erişimi öncesinde, uygulamalı bir eğitim seminerinin yapılmasının yararı olacağı düşünüldü. 
3-4 Eylül 2002 tarihlerinde Boğaziçi Üniversitesinin ev sahipliğinde yapılan seminere, kataloglamada MARC standardı kullanan ve 2002 yilında "OCLC Online Cataloguing'e" üye olmayı düşünen 21 kurumun katalog uzmanları katıldı. OCLC uzmanı Stuart Hunt tarafından ilk gün "CatMe" arayüzü kullanılarak çevrimiçi kataloglama, 2. gün ise "CORC" konusunda uygulamalı eğitim verildi. Bu semineri takiben "WorldCat" bir ay süre ile katılımcı kütüphaneçilerin denemesi için erişime açıldı.

Deneme sürecindeki kullanım istatistiklerini incelemek ve sonuçlarını tartışmak üzere 22 Kasım 2001 tarihinde Ankara Üniversitesinin ev sahipliğinde bir toplantı düzenlendi. Toplantıda "Worldcat ve CORC, FirstSearch ve PAIS kısaca tanıtıldı, deneme ve bir yıllık kullanım istatistikleri detaylı tablolar halinde açıklanarak yorumlandı. Bu toplantının sonucunda;

- OCLC FirstSearch'ün 13 üye tarafından yenilemesi ve 3 yeni üyenin katıımı ile 2002 yılında devamına,

- Tam metin erişim için kullanımı en yüksek 6 yayınevi seçilerek, fiyat teklifi istenmesine karar verildi.

- Ayrıca deneme sürecinde yoğun kullanan iki üniversitenin katılımı ile PAIS, beş üniversitenin katılımı ile BioOne için iki alt grup oluşturuldu.

- 2 Ocak 2002 tarihinden başlamak üzere, dördü konsorsiyum üyesi olan 11 üniversite tam üye olarak WorldCat'i kullanarak çevrimiçi kataloglama yapmaya başladı.

\section{UNAKCat}

Derneğimizin UNAKCat Grubunu kurmasındaki hedefleri arasında; kataloglamanın belli bir standartta yapılmasını, üniversitelerimizin ve araştırma merkezlerimizin yurtdışında tanınmasını, Türkçe kitapların uluslararası platformda yer almasını sağlamayı sayabiliriz.

Bir sonraki hedefimiz ise, üye kütüphanelerin katalogladığı kitapların kayıtlarının yerel bir sunucuda depolanarak bir toplu katałog oluşturmaktır.

Paylaşıma açık çevrimiçi kataloglama sistemi olan "WorldCat Online Catalouging" kullanılarak her tür ve formatta bilgi kaynağı, MARC21 standardı 
ile kataloglanabilmekte, WorldCat'te mevcut kayitlar kopyalanarak kendi katalog sistemine -kütüphaneye özel değişiklikler yapılarak- aktarılabilmektedir. Worldcat'de bulunmayanların yeni bir kayıt olarak kataloglanmasina olanak sağlanmıştır. Her iki biçimde oluşturulan katalog kayıtları, işlem yapan kütüphanenin adı ile sisteme girmektedir. Toplu kataloğa girilen her bir orijinal kayıt için alınan kredi, taranan ałtı kayıt değerindedir.

\section{Sonuç}

Her yıl yapılmasına karar verilen ÜNAK/OCLC Konsorsiyum Toplantısının ikincisi, 2002 yılında Pamukkale Üniversitesinin daveti üzerine 5-7 Mayıs 2002 tarihinde Denizli'de yapılması planlanmıştır. OCLC'den Rick Dawson ve John Dowd tarafından verilecek seminerde, Cataloguing/CORC, FirstSearch yenilikleri, ECO, netLibrary ve WeblLL üzerinde geniş bilgi verilerek, ilave olarak katılımcıların sorularının tartış|lacağı bir oturum düzenlenecektir.

Bir yıllık kullanımın ardından mevcut oniki üye kütüphane aboneliğini yenilerken, dört yeni üniversite (Atatürk, Kocaeli, Muğla ve Sakarya Üniversite(er) bu konsorsiyuma katılmış, bununla birlikte dört üniversite (Ankara, Çukurova, Selçuk ve Trakya Üniversiteleri) çeşitli nedenlerle konsorsiyumdan ayrılmıştır. Bu durumda, 2002 yılında ÜNAKNOCLC Konsorsiyumları ve Alt Gruplarını oluşturan üye kurumlar şunlardır: UNAKJOCLC Konsorsiyumunda Atatürk, Boğaziçi, Dokuz Eylül, Doğu Akdeniz, Ege, Erciyes, Hacettepe, Kocaeli, Mersin, Muğla, Ondokuz Mayıs, Pamukkale, Sakarya ve Yüzüncü Yll Üniversiteleri ile GATA ve ULAKBiM; BioOne'da Atatürk, Dokuz Eylül, Erciyes, Hacettepe ve Muğla Üniversiteleri, PAIS International veri tabanında $\mathrm{Ha}$ cettepe Üniversitesi, UNAKCat Grubunda ise Abant Izzet Baysal, Bikent, Boğaziçi, Çankaya, Doğu Akdeniz, Işık, Orta Doğu Teknik, Pamukkale ve Sabana Üniversitesiteleri ile TED Ankara Koleji yer almaktadır. 


\section{Ek: ECO'da yer alan yayınevleri}

(Yanında * işareti olanlar kurumların abone oldukları dergilerin elektroniklerini ücretsiz erişime açmayı kabul eden yayınevleridir).

Academic Press IDEAL

* Adis International Limited (2002)

* American Mathematical Society $(2001,2002)$

American Meteorological Society

BioOne

* Blackwell Publishers (2001, 2002)

Blackwell Science

* Brill Academic Publisher (2001, 2002)

* The British Psychological Society (2001, 2002)

* Brookings Institution Press (2001, 2002)

* Cambridge University Press $(2001,2002)$

* Carfax Publishing Ltd., part of the Taylor \& Francis Group $(2001,2002)$ CRC Press LLC

CSIRO Publishing

Current History

" Edward Arnold Publishers Ltd. (2001, 2002)

* Emerald (2001, 2002)

Fairmont Press

* Guilford Publications (2001, 2002)

Harcourt Health Sciences

* The Haworth Press, Inc. (2001, 2002)

* Humana Press (2001)

Imprint Academic

Indiana University Press

* Institution of Chemical Engineers (2001, 2002) 
* Institution of Mechanical Engineers (2001, 2002)

* international Union of Pure and Applied Chemistry (2002)

* IOS Press (2001, 2002) Jossey-Bass Publishers Karger Publishers Kluwer Academic Publishers Kluwer Academic-Plenum-Human Sciences Press

* Lawrence Erlbaum Associates (2001, 2002) Marcel Dekker, Inc.

Mary Ann Liebert, Inc.

Melbourne Journa: of International Law

* The Mineralogical Society of Great Britain \& Ireland $(2001,2002)$

* MIT Press (2001, 2002)

* Munksgaard International Publishers (2002)

National Research Council of Canada

Nature Publishing Group

The Ohio State University Press

* OECD-Organisation for Economic Co-Operation \& Development (2002)

* Oxford University Press (2001, 2002)

Palgrave Publishers

* Project HOPE $(2001,2002)$

Project Muse

RAND

* Routledge, part of the Taylor \& Francis Group $(2001,2002)$

- The Royal Society $(2001,2002)$

* Royal Society of Chemistry (2001, 2002)

* Royal Society of Medicine Press Ltd. $(2001,2002)$

* Sage Publications (2001, 2002) 
* Scandinavian University Press (2001)

* Seismological Society of America (2001, 2002)

* Society for Applied Spectroscopy (2001, 2002)

* Swets \& Zeitlinger Publishers (2001, 2002)

* Taylor \& Francis $(2001,2002)$

United States Society for Education Through Art

University of California Press

* University of Wisconsin Press $(2001,2002)$ WB Saunders IDEAL

" Walter de Gruyter GmbH \& Co. (2001, 2002)

Wiley Subscription Services, Inc. A Wiley Company

World Scientific Publishing Company 


\section{FOR IMMEDIATE RELEASE}

FOR MORE INFORMATION:

Nita Dean $+1-614-761-5002$

nita_dean@oclc.org

Kathy Fryer +011441214564656

kathy fryer@ock.org

\section{TURKISH CONSORTIUM TO USE FIRSTSEARCH}

DLBLIN, Ohio, April 13, 2001-Following a four-week trial, 13 members of the Turkish University and Research Librarians Association (UNAK) formed a consortium to use the OCLC FirstSearch service. Since the libraries began using FirstSearch in early January, two more libraries have joined the consortium.

The UNAK consortium has focused on full-text capability combined with access to OCLC's unique databases available through the OCLC Base Package with Full Text option, which includes WorldCat, OCLC FirstSearch Electronic Collections Online (bibliographic index), OCLC ArticleFirst, OCLC ContentsFirst, OCLC NetFirst, OCLC Union Lists of Periodicals, OCLC PapersFirst, OCLC ProcedingsFirst, ERIC, GPO, MEDLINE, World Almanac and H.W. Wilson Select Plus.

"Fifteen OCLC consortium members are very pleased to have access to a huge dalabase that covers all subjects with reasonable prices," said Adile Gunden, president of UNAK and deputy director of the Hacettepe University Libraries, Ankara Turkey. "Besides this, we can access a wide range of electronic periodicals through the Electronic Collections Online database in FirstSearch."

"This agreement offers UNAK libraries access to quality content coupled with links to online full text for immediate delivery to the desktop," said Nick Rawson, director, Library Services, (over) 
Turkish consortium using FirstSearch

Page 2

OCLC Europe, the Middle East \& Africa. "We are delighted to be working with UNAK on this

important projech, and we look forward to strengthening our links with Turkish libraries in years

to come."

The Turkish University and Research Librarians Association (UNAK) aims to investigate the problems of university and research libraries, documentation and information centres and related special libraries with reference to the swiftly developing technologies; to make international comparisons of problems and their solutions; to search for the problems of personnel working at the information centres; to provide aid to the application of new technologies, etc. In short, their mission is to try to adapt or introduce to contemporary functions the tasks undertaken by the Turkish information centres and libraries <htp://www. unokorg.tr/>.

Headquartered in Dublin, Ohio, OCLC Online Computet Library Center is a nonprofit organization that provides computer-based cataloging, reference, resource sbaring and preservation services to 39,000 libraries in 76 countries and territories. OCLC was founded in 1967 to improve access to the world's information and reduce in formation costs, and conducts ongoing research to develop technologies to support that mission. Forest Press, a division of OCLC since 1988, publishes the Dewey Decimal Classification system.

In the United States, more information is availabie (via telephone: $+1-614-764-6000$ or 1-800-848-5878; fax: +1-614-764-6096; or e-mail: ocle@oclcorg). In Europe, the Middle East and Africa, contact the OCLC Europe office, located in Birmingham, United Kingdom (pbone: +44 121 456 4656; fax: +44 121456 4680; or e-mail: europe@ocic.org). In Asia and the Pacific region, contact the OCLC Asia Pacific office in Dublin, Ohio (phone: +1-614-764-6189; fax: +1-614-764-4331; or e-mail: asia_pacific@oclc.org). In Canada, contact the OCLC Canada office in Montreal, Quebec (phone: +1-450-658-6583 or 1-888-658-6583; fax: +1-450658-6231; or e-mail: canada@oclcorg). In Latin America and the Caribbean, contact the OCLC Latin America and the Caribbean office in Dublin, Ohio (phone: +1-614-761-5196; fax: +1-614-718-1026; or e-mail: america_latina@oclc.ong).

More information about OCLC and OCLC regional service partners is available on the web $<$ hitp.//www, oclc,org/s.

$$
-0-
$$

ArticleFirst, ContentsFirst, Dewey, Dewey Decimal Classification, FirstSearch, Forest Press, NetFirst, OCLC, PapersFirst, ProceedingsFirst and WorldCat are registered trademarks of OCLC. Electronic Collections Online is a trademark of OCLC. 